\title{
L'agriculture en famille : travailler, réinventer, transmettre
}


Les coordinateurs et l'ensemble des auteurs remercient chaleureusement les relecteurs anonymes pour leur contribution à la qualité des textes publiés dans cet ouvrage.

Photographies en couverture :

- Famille sur le tracteur, (C) Anne Sourdril,

- Coteaux de Gascogne, (C) Gérard Balent.

Imprimé en France

ISBN : 978-2-7598-1192-2

Cet ouvrage est publié en Open Access sous licence creative commons CC-BY-NC-ND (https://creativecommons.org/licenses/by-nc-nd/4.0/fr/) permettant l'utilisation non commerciale, la distribution, la reproduction du texte, sur n'importe quel support, à condition de citer la source.

C INRA-SAD, 2014 